\title{
CONTRIBUIÇÕES DE UMA RESIDÊNCIA EM PSIOUIATRIA E SAÚDE MENTAL NA FORMAÇÃO DOS ENFERMEIROS EGRESSOS
}

John Victor dos Santos Silva ${ }^{1}$ https://orcid.org/0000-0003-4671-102X

Thyara Maia Brandão ${ }^{1}$

http://orcid-org/0000-0003-4630-6956

Objetivo: conhecer as contribuições de um programa de residência em psiquiatria e saúde mental na formação dos enfermeiros egressos. Métodos: trata-se de uma pesquisa qualitativa, exploratória, realizada com 10 enfermeiros egressos. A produção de dados foi através de entrevista semiestruturada e gravação de áudio, analisados à luz da técnica de Análise de Conteúdo, na modalidade Análise Categorial, proposta por Bardin. Resultados: das falas dos participantes, emergiram as seguintes categorias: contribuições na formação em saúde mental; contribuições como profissional de enfermagem; e contribuições na vida pessoal. Conclusão: As contribuições foram tanto no desenvolvimento de habilidades para a assistência em saúde mental como na profissão de enfermeiros, para atuar em todos os níveis de saúde. Houve, também, contribuições na vida pessoal, promovendo o amadurecimento para o enfrentamento das dificuldades e situações mais diversas no trabalho e na vida.

Descritores: Enfermagem; Psiquiatria; Saúde mental; Internato não médico.

\section{CONTRIBUTIONS OF A RESIDENCE IN PSYCHIATRY AND MENTAL HEALTH IN THE FORMATION OF NURSES.}

\section{ABSTRACT}

Objective: to know the contributions of a residency program in psychiatry and mental health in the training of registered nurses. Methods: it is a qualitative, exploratory research carried out with 10 registered nurses. The data production was through semi-structured interview and audio recording, analyzed in light of the Content Analysis technique, in the category Categorical Analysis modality, proposed by Bardin. Results: the following categories emerged from the participants' speeches: contributions in mental health training; contributions as a nursing professional; and contributions in personal life. Conclusion: The contributions were both in the development of skills for mental health care as in the profession of nurses, to act at all levels of health. There were also contributions in the personal life, promoting the maturity to face the difficulties and most diverse situations in work and life.

Descriptores: Nursing; Psychiatry; Mental Health; Internship, Nonmedical.

\section{CONTRIBUCIONES DE UNA RESIDENCIA EN PSIQUIATRÍA Y SALUD MENTAL EN LA FORMACIÓN DE LOS ENFERMEROS EGRESOS.}

Objetivo: conocer las contribuciones de un programa de residencia en psiquiatría y salud mental en la formación de los enfermeros egresados. Métodos: Es una investigación cualitativa, exploratoria realizada con 10 enfermeras registradas. La producción de datos se realizó a través de una entrevista semiestructurada y una grabación de audio, analizada a la luz de la técnica de Análisis de contenido, en la categoría Modalidad de análisis categórico, propuesta por Bardin. Resultados: de las palabras de los participantes surgieron las siguientes categorías: contribuciones en la formación en salud mental; contribuciones como profesional de enfermería; y contribuciones en la vida personal. Conclusión: Las contribuciones fueron tanto en el desarrollo de habilidades para la asistencia en salud mental como en la profesión de enfermeros, para actuar en todos los niveles de salud. También hubo contribuciones en la vida personal, promoviendo la maduración para el enfrentamiento de las dificultades y situaciones más diversas en el trabajo y en la vida.

Descriptores: Enfermería; Psiquiatría; Salud Mental; Internado no Medico. 


\section{INTRODUÇÃO}

Os Programas de Residência em Saúde são modalidades de pós-graduação Lato Sensu, mediante as quais o enfermeiro pode obter o título de especialista em determinada área de conhecimento, ofertadas por instituições de ensino ou de saúde públicas e privadas. A Residência tem como principal característica o desenvolvimento de habilidades técnico-científicas através de práticas nos serviços de saúde.(1)

Esses programas são regulamentados pela Comissão $\mathrm{Na}^{-}$ cional de Residência Multiprofissional em Saúde (CNRMS) que avalia e qualifica os programas no Brasil. A estrutura das residências compreende uma carga horária de 60 horas semanais, durante dois anos, onde o residente é remunerado, não podendo ter vínculo empregatício.(2)

Os programas seguem os princípios e diretrizes do Sistema Único de Saúde (SUS) e permitem a experiência da integração ensino-serviço-comunidade, norteando as ações de educação e trabalho baseados nas necessidades dos indivíduos, famílias e comunidades em que o programa estiver inserido. (2)

As Residências são alternativas existentes também para especialização em saúde mental; bastante procuradas principalmente pelos enfermeiros recém-formados como opção de qualificação profissional. Essa modalidade de pós-graduação proporciona, ao enfermeiro. o desenvolvimento de competências assistenciais e gerenciais. ${ }^{(3)} \mathrm{Com}$ o crescente número de serviços de saúde mental existentes no Brasil, as residências são excelentes estratégias de qualificação profissional para vivenciar a assistência às pessoas com sofrimento mental nos próprios serviços, o que contribui para formar enfermeiros especialistas para o trabalho em saúde mental.(4)

O programa de residência de Enfermagem em Psiquiatria e Saúde Mental, objeto deste estudo, é ofertado por uma universidade pública do nordeste do Brasil, cujo início ocorreu no ano de 2007, ofertando duas vagas anualmente para enfermeiros. O candidato realiza prova objetiva e de títulos para ingressar no programa, recebendo formação através do ensino e trabalho em um Hospital Psiquiátrico (HP) e em serviços substitutivos de saúde mental da Rede de Atenção Psicossocial (RAPS) do estado, formando, até o momento, mais de 20 enfermeiros especialistas.

Desta forma, percebe-se a necessidade de conhecer de que forma os programas de residência em saúde mental contribuem para a formação dos profissionais na perspectiva da saúde pública e através das práticas nos serviços. Sendo assim, o presente trabalho tem como objetivo conhecer as contribuições de um programa de residência em psiquiatria e saúde mental na formação dos enfermeiros egressos.

\section{MÉTODO}

\section{Tipo de estudo}

Estudo exploratório com abordagem qualitativa. A escolha pela abordagem qualitativa ocorreu pela possibilidade do aprofundamento nas subjetividades dos sujeitos, extraindo, de suas percepções, os significados sobre as questões da vida em geral(5). O estudo exploratório, por sua vez, permite essa aproximação do pesquisador com o objeto pesquisado, da forma como ele se apresenta e dentro do seu contexto social.(6)

\section{Participantes da pesquisa}

O estudo foi realizado com os enfermeiros egressos do programa de Residência em Enfermagem em Psiquiatria e Saúde Mental de uma universidade pública, localizada no nordeste do Brasil. Participaram da pesquisa 10 enfermeiros egressos. A amostra inicial seguiu os preceitos da pesquisa qualitativa que não se limita ao número de sujeitos, mas às subjetividades e contribuições de cada um ${ }^{(5)}$. Já o número final da amostra foi estabelecido pelo critério de saturação que determina a interrupção dos sujeitos quando os dados produzidos se tornam repetitivos ${ }^{(7)}$. Os critérios de inclusão foi ter concluído o programa de residência até março de 2018, sendo excluídos os que estavam de férias ou de licença.

\section{Cenário do estudo}

O cenário do estudo foi bastante diversificado, sendo utilizadas as dependências de universidades e também os locais de trabalho dos participantes. Esses locais foram acordados entre os participantes e os pesquisadores de forma a alterar minimamente a rotina dos egressos.

\section{Coleta de dados}

A coleta de dados compreendeu o período de Abril a Agosto de 2018. Foi realizada busca ativa para o recrutamento dos participantes, após contato com a Supervisão de Pós-Graduação Latu Sensu da universidade. A abordagem aos participantes foi feita de forma individual.

Para a produção dos dados foi utilizada a técnica da entrevista semiestruturada com roteiro produzido pelos pesquisadores de acordo com os objetivos da pesquisa. O roteiro contou com 10 perguntas abertas permitindo a melhor exploração da percepção dos participantes; a duração média das entrevistas foi de 30 minutos. Foi realizado também gravação de áudio da entrevista, com o consentimento dos participantes.

\section{Análise dos dados}

Todo o material produzido foi transcrito na íntegra e anali- 
sado à luz da técnica de Análise de Conteúdo, na modalidade Análise Categorial. A análise categorial permite que os pesquisadores extraiam categorias que emergem a partir das unidades das falas dos sujeitos, dos sentidos que eles oferecem para cada questão relacionada aos objetivos da pesquisa. ${ }^{(8)}$

A Análise seguiu três passos fundamentais: o primeiro passo foi fazer uma leitura flutuante prévia das falas transcritas, no intuito de começar a identificar as unidades das falas. O segundo passo foi atribuir categorias as unidades das falas dos sujeitos, através dos sentidos expressados. No terceiro e último passo, foi realizado o tratamento dos dados, quando os pesquisadores fizeram os agrupamentos das unidades das falas a partir das categorias que emergiram. ${ }^{(5)}$

\section{Procedimentos éticos}

Para garantir o anonimato dos participantes, os pesquisadores adotaram o termo "Egresso" para nomeá-los, seguidos de um número. Este estudo seguiu os preceitos éticos da resolução no. 466/12 do Ministério da Saúde, sendo submetido ao Comitê De Ética em Pesquisa (CEP) e aprovado sob o CAAE no 84575418.5.0000.5011. Os participantes assinaram o Termo de Consentimento Livre e Esclarecido.

\section{RESULTADOS}

A maioria dos enfermeiros egressos entrevistados eram mulheres e haviam entrado no programa logo após o término da graduação. Todos escolheram a residência de Enfermagem em Psiquiatria e Saúde Mental por ter vivenciado alguma experiência satisfatória durante a graduação.

Das falas dos participantes, emergiram as seguintes categorias: contribuições na formação em saúde mental; contribuições na profissão de enfermeiro; e contribuições na vida pessoal.

\section{Contribuições na formação em saúde mental}

A primeira contribuição, segundo os relatos dos egressos, foi justamente o aprendizado sobre as questões que envolvem a saúde mental, desde a reforma psiquiátrica até as politicas e os serviços de saúde mental, pois a residência lhes foi uma experiência rica e intensa.

Segundo os egressos, a experiência do programa permitiu uma vivência na Rede de Atenção Psicossocial (RAPS) do estado a nível municipal ou estadual, possibilitando, aos egressos, desenvolverem habilidades para o trabalho na saúde mental, aperfeiçoando-os cada vez mais para uma assistência mais completa e eficaz:

“É uma experiência muito diversificada. Na residência, a gente tem a oportunidade de conhecer a rede, de conhe- cer as pessoas que estão nessa rede, de poder conhecer um pouco a gestão e conhecer a ponta e saber que existem problemas lá na ponta que dependem da gestão e questões da gestão que dependem também da atuação desse profissional lá na ponta. [...] Nós realmente temos o conhecimento do todo, né, da oportunidade de conhecer por exemplo, o fluxo de como acontece o funcionamento dos serviços e que são pontos positivos que nos preparam para trabalhar em qualquer ponto da rede de saúde mental" (Egresso 4).

Essa aproximação direta com toda a RAPS, segundos os egressos, possibilitou uma compreensão maior, principalmente, sobre a organização, funcionamento e financiamento de toda a rede. Os egressos relatam que existem questões na saúde mental que só foi possivel conhecerem através da residência, e que em outro curso de qualificação profissional ou especialização, mesmo ofertando o mesmo título, de especialista em saúde mental, não lhes seria oportunizada toda a compreensão da administração pública com relação à rede.

Os egressos trazem ainda que esse contato com a gestão capacitou-os para o trabalho na direção de serviços de saúde em todos os níveis de atenção, favorecendo a experiência de atuar gerindo as dificuldades apresentadas nos serviços em qualquer esfera de trabalho, público ou privada:

"Foi uma experiência muito rica de conhecer a área de planejamento, como é que se dá a atuação dos gestores na secretaria municipal de saúde, na secretaria estadual. Houve impasses que acontecem desde a questão mesmo dos recursos financeiros, dos projetos e isso me ajudou a entender melhor também a minha atuação no serviço, porque muitas vezes a gente questiona porque que as coisas não acontecem da forma que deveria ser e ai por ter esse contato na rede, na residência tanto na assistência como na gestão, a gente consegue entender melhor os processos" (Egresso 9).

Os egressos falam que se sentem mais capacitados para o trabalho em qualquer nivel de atenção, seja na assistência ou gestão, pelo desenvolvimento dessas habilidades durante a experiência que tiveram na residência.

\section{Contribuições na profissão de enfermeiro}

Todo o processo de formação, durante o período em que estiveram no programa de residência em saúde mental, contribuiu, de forma significativa, não apenas na formação de profissional da saúde mental, mas também como enfermeiros generalistas. 
Nas falas, o aprendizado contribuiu para aperfeiçoar suas habilidades terapêuticas, permitindo que assumam cargos e funções diversificadas na assistência, no ensino e gestão. Assumir a responsabilidade como profissional, durante a residência, possibilitou uma evolução na autonomia desses profissionais, pois, para a maioria, foi sua primeira experiência como profissional:

"Com o que eu aprendi na residência eu me sinto preparada pra trabalhar em qualquer lugar. Tanto na gestão como nos serviços, porque eu aprendi a analisar as situações, ponderar, pensar, pensar naquela pessoa que está sendo cuidada. E acredito que a experiência da residência me proporcionou mais essa mudança de atitude, de julgamento, de conhecimento também e a prática, tanto na saúde mental, como na enfermagem" (Egresso 6).

Os egressos relataram que durante o tempo que estava no programa não eram vistos como estudantes, mas como enfermeiros e que faziam parte do trabalho, o que contribuiu para que pudessem amadurecer nos serviços. Eles mesmos não se sentiam mais como estudantes, mas como profissionais com a responsabilidade de exercer a função de enfermeiro, pois as demandas thes exigiam e thes cobravam isso:

"A forma como cobram aquilo de você, você acaba se deparando com a responsabilidade de enfermeira. E aí? $\mathrm{E}$ esse remédio? Então, eles cobram de você uma coisa que você acaba também se cobrando. Porque independente de qualquer coisa você é enfermeira" (Egresso 2).

A residência em saúde mental, segundo os egressos, demanda um contato e vínculo muito estreito com os usuários e o desenvolvimento de habilidades, como a escuta qualificada, comunicação terapêutica, acolhimento, cuidados referente ao emocional dos sujeitos, o que aprenderam a ampliar de forma mais eficiente, em todos os serviços de saúde nos quais trabalham, sejam eles de saúde mental ou não, mudando suas posturas completamente:

“Hoje eu converso com o paciente de forma muito mais tranquila, né. Me deu segurança em identificar alguns sintomas, sinais, em relação a alguns diagnósticos, então me aproximou a alguns transtornos que eu não tinha contato antes, os casos graves eu consigo perceber e acompanhar, né, ver a evolução disso, assim eu consigo valorizar de forma melhor as questões subjetivas dos pacientes" (Egresso 5).

\section{Contribuições na vida pessoal}

Uma questão bastante interessante que emergiu das falas dos egressos foi a contribuição na vida pessoal, principalmente no que diz respeito ao amadurecimento, relatado como algo inerente ao processo de formação da residência. Os egressos dizem que os reflexos desse amadurecimento são vistos até os dias de hoje em tudo o que fazem.

"A gente desenvolve também maturidade, né. Num tem aquele ditado que diz que a gente aprende mais com a dor do que com o amor? Então! Assim... É tudo tão árduo, tão intenso, que a gente acaba desenvolvendo uma maturidade. E o legal é que essa maturidade nos ajuda a lidar com tudo na vida. A gente aprende a lidar com amigos, familiares, colegas de trabalho, com as dificuldades, com tudo mesmo" (Egresso 8).

Esse amadurecimento que a residência proporcionou aos egressos trouxe ganhos também na forma como vêem e percebem o mundo e, principalmente, as relações interpessoais. O fato de estar constantemente trabalhando com o sofrimento mental dos usuários durante a passagem nos serviços de saúde mental de Alagoas fez com que compreendessem questões subjetivas da vida de outra forma, permitindo-lhes uma melhor posição diante das dificuldades:

"Acho que hoje se eu sou o que sou foi graças à residência também, porque querendo ou não lidar direto com o sofrimento do outro isso te transforma. Eu acho que eu hoje tenho um olhar diferenciado em relação às pessoas que eu convivo por conta disso. Por estar ali sempre e vendo as necessidades do outro, o sofrimento intenso do outro, eu acho que isso me mudou enquanto pessoa" (Egresso 7).

Segundo os egressos, a experiência de vivenciar a residência durante os dois anos de programa é tão intenso que eles relatam que sua vida é transformada. A transformação aconteceu na sua percepção de mundo, em suas atitudes, comportamentos, responsabilidades, disciplina frente aos seus compromissos:

“Eu posso dizer que eu era uma pessoa quando eu entrei na residência e que quando eu saí me tornei outra" (Egresso 3).

\section{DISCUSSÃO}

A Enfermagem é uma profissão historicamente exercida por mulheres, o que justifica a maioria dos egressos serem mulheres ${ }^{(9)}$. Os enfermeiros recém-formados são os que mais 
procuram pela residência por ser uma opção de adquirir experiência profissional. Já para os enfermeiros com mais tempo de formação a residência se torna desinteressante, porque a maioria já está com estabilidade profissional no mercado. ${ }^{(3)}$

A disciplina de saúde mental é obrigatória na grade curricular do curso de graduação em enfermagem, mas são poucos estudantes que possuem afinidade com a área, o que justifica sua pouca procura frente aos demais programas de residência para enfermagem. . $^{(10)}$

A formação em saúde mental não é uma exclusividade dos programas de residências. Existem outros cursos na modalidade latu sensu para adquirir conhecimento teórico sobre o trabalho, porém poucos são os que oferecem uma parte prática para os profissionais. ${ }^{(11)}$

A contribuição na formação em saúde mental é rica, pois possibilita experiência profissional através de contínua prática nos serviços. Os residentes são direcionados para os principais dispositivos de saúde mental da Rede de Atenção Psicossocial, onde $80 \%$ da carga horária é destinada para a prática nos serviços e os outros $20 \%$ destinados a formação teórica. ${ }^{(12)}$

Essa contínua prática nos serviços capacita os profissionais para trabalhar na assistência direta às pessoas em sofrimento mental em todos os níveis de atenção, sejam nos ambulatórios, nos CAPS, na urgência e emergências em saúde mental, na atenção básica, entre outros. Os residentes são capacitados para prestar cuidados em muitas circunstâncias e situações, tendo a prática sempre alinhada com a teoria constantemente. ${ }^{(13)}$

A passagem pela gestão é outro ponto bastante importante da residência. Conhecer a estruturação e organização da rede permite uma visão mais ampliada sobre a saúde mental, facilitando a compreensão sobre os aspectos necessários para o funcionamento dos serviços. Essa experiência capacita para a gestão dos demais serviços de saúde. ${ }^{(14)}$

A contribuição para a profissão do enfermeiro é perceptível no desenvolvimento de habilidades para o trabalho de enfermagem em diversos serviços de saúde, pois é uma contribuição direta pra a capacitação dos enfermeiros; em alguns dispositivos de saúde mental, porém, o trabalho se distancia um pouco das características dos serviços hospitalares. ${ }^{(15)}$

Apesar de estudantes, eles possuem atribuições e devem desempenhar suas atividades como profissionais do serviço, o que thes pode causar certa insegurança e medo, especialmente no seu início, pela pouca experiência e grandes responsabilidades que lhes são impostas. Com frequentes prática, esses residentes vão se aperfeiçoando e desenvolvendo competências necessárias para a segurança durante a execu- ção de suas tarefas. ${ }^{(11)}$

As habilidades mais desenvolvidas pelos residentes, nos serviços de saúde mental, são as tecnologias leves, como a escuta qualificada, comunicação terapêutica, acolhimento, principais instrumentos utilizados nos serviços de saúde mental. O perfil do público de cada serviço define quais estratégias serão mais utilizadas durante esse processo de formação. ${ }^{(12)}$

As contribuições na vida pessoal do enfermeiro são bastante evidentes, especialmente a partir das relações interpessoais, pois os serviços que percorrem exigem isso. Desta forma, é impossivel não ser modificado e amadurecer com as constantes relações e vínculos estabelecidos durante os dois anos de programa, em todos os serviços que passam. ${ }^{(16)}$

O processo de formação nos programas de residências é bastante intenso e a cobrança é muito grande, promovendo o desenvolvimento de maturidade para a vida. Existe um ganho muito grande com relação à mudança de comportamento atitude, a disciplina no desenvolvimento de suas atividades, tanto na profissão como na vida pessoal.(17)

Os programas de residência são considerados pelos profissionais e pelo mercado de trabalho como o padrão ouro para a formação de qualquer profissional, por todas as vantagens apresentadas. O residente egresso, em comparação aos demais profissionais, consegue se destacar em cargos superiores mais rapidamente que os demais profissionais. ${ }^{(14)}$

Essa realidade ocorre pelo reconhecimento dos serviços de saúde da extensiva e duradoura prática que os enfermeiros exercem durante o programa. O mercado de trabalho nota o diferencial desses profissionais, valorizando o profissional que já tem experiência com os serviços da rede em saúde mental.(12)

\section{Limitações do estudo}

A principal limitação do estudo está relacionada à dificuldade de contatar os egressos para participarem do estudo, além de trazer apenas a visão dos egressos, não sendo possivel conhecer a percepção dos demais personagens que compõem o programa, como preceptores, coordenadores, dentre outros.

\section{Contribuições para a prática}

Este estudo facilita a compreensão por parte dos profissionais, gestores e usuários da importância do programa de residência em saúde mental e da relevância da inserção dos enfermeiros residentes nos serviços de saúde mental, possibilitando que esses futuros profissionais atuem na área de uma forma mais completa e fundamentada nas reais práticas realizadas no trabalho em saúde mental.

\section{CONSIDERAÇÕES FINAIS}

O presente trabalho retrata parte das contribuições de 
um programa de residência de psiquiatria e saúde mental na formação dos enfermeiros egressos, que, na sua maioria, são mulheres e ingressaram no programa logo após a formação.

As contribuições do programa ocorrem tanto na formação como profissionais da saúde mental, desenvolvendo habilidades para a gestão e assistência à pessoa em sofrimento mental, como no exercício da profissão de enfermeiros, o que thes proporcionou o desenvolvimento profissional para atuar em todos os níveis de saúde. Houve, também, contribuições na vida pessoal, promovendo o amadurecimento para o enfrentamento das dificuldades e situações mais diversas no trabalho e na vida, além de melhorar as relações interpessoais. Embora seja uma vivência

\section{REFERÊNCIAS}

1. Conselho Federal De Enfermagem. Resolução n으 0459 de 21 de Agosto de 2014. Estabelece os requisitos minimos para o registro de Enfermeiro Especialista, na modalidade de Residência em Enfermagem. Brasilia: COFEN. 2014 [cited 2018 Nov 13]. Available from: http://www.cofen.gov. br/resolucao-cofen-no-04592014_26170.html.

2. Ministério da Educação (BR). Portaria Interministerial MEC/MS № 1.077, de 12 de Novembro de 2009. Dispõe sobre a Residência Multiprofissional em Saúde e a Residência em Área Profissional da Saúde, e institui o Programa Nacional de Bolsas para Residências Multiprofissionais e em Área Profissional da Saúde e a Comissão Nacional de Residência Multiprofissional em Saúde. Brasilia: Gabinete do Ministro. 2009 [cited 2018 Nov 13]. Available from: http://portal.mec.gov.br/index. php?option=com_docmanEview=downloadEalias=15462-por-107712nov-2009\&Itemid=30192.

3. Evangelista ALP, Frota AC, Torres RBS, Barreto ICHC. Residência integrada em saúde mental: cuidado à rede de atenção psicossocial. Rev Bras Promoç Saúde. 2018 [cited 2019 Jun 21];31(4):1-11. Available from: https://periodicos.unifor.br/RBPS/article/view/8774/pdf.

4. Macedo JP, Abreu MM, Fontenele MG, Dimenstein M. A regionalização da saúde mental e os novos desafios da Reforma Psiquiátrica brasileira. Saúde e Sociedade. 2017 [cited 2018 Nov 13]:26(1):155-170. Available from: http:// www.scielo.br/pdf/sausoc/v26nl/1984-0470-sausoc-26-01-00155.pdf.

5. Minayo MCS. O desafio do conhecimento: pesquisa qualitativa em Saúde. $12^{a}$ ed. São Paulo: Hucitec; 2010.

6. Malvezzi CD, Gerhardinger HC, Santos LLP. Toledo VP, Garcia APRF. Adherence to treatment by the staff of a mental health service: an exploratory study. Online braz j nurs [internet] 2016 Jun [cited 2019 Jun 21]:15(2):177-187. Available from: http://www.objnursing.uff.br/index.php/ nursing/article/view/5201.

7. Minayo MCS. Amostragem e saturação em pesquisa qualitativa: consensos e controvérsias. Revista Pesquisa Qualitativa. 2017 [cited 2019 Jun 21]:5(7):1-12. Availabre from: https://editora.sepq.org.br/index.php/ rpq/article/view/82/59.

8. Bardin L. Análise de conteúdo. São Paulo: Edições 70; 2011.

9. Machado MH (Coord), Aguiar WF, Lacerda WF, Oliveira E, Lemos W. Wermelinger M, et al. Características gerais da enfermagem: o perfil sócio demográfico. Enfermagem em Foco. 2016 [cited 2018 Nov 13];7(esp):914. [acesso em: 13 nov. 2018] Available from: http://revista.cofen.gov.br/ index.php/enfermagem/article/view/686/296. apenas de dois anos, percebe-se que as contribuições são bastante significativas e superam as dificuldades durante o percurso

Sugere-se que sejam realizados novos estudos para conhecer os demais programas de residência que existem no Brasil, possibilitando conhecer se as contribuições aqui apresentadas também corroboram aos egressos dos demais programas.

\section{Contribuições dos autores:}

JVSS: concepção e desenho, análise e interpretação dos dados e redação do artigo. TMB: concepção e desenho, revisão crítica e revisão final.

10. Vargas D, Maciel MED, Bittencourt MN, Lenate JS, Pereira CF. O ensino de enfermagem pisiquiátrica e saúde mental no Brasil: análise curricular da graduação. Texto \& Contexto-Enfermagem. 2018 [cited 2018 Nov 13];27(2): e2610016. Available from: http://www.scielo.br/pdf/tce/ v27n2/0104-0707-tce-27-02-e2610016.pdf.

11. Onocko-Campos R, Emerich BF, Ricci EC. Residência Multiprofissional em Saúde Mental: suporte teórico para o percurso formativo. Interface (Botucatu). 2019 [cited 2019 Jun 21];23:el70813. Available from: https:// www.scielosp.org/pdf/icse/2019.v23/el70813/pt.

12. Ponte Neto OA, Silva MMS, Saraiva MJG, Dias MSA, Vasconcelos MIO, Cavalcante ASP. Parente JRF. Auto avaliação como estratégia educativa no contexto do programa de residência multiprofissional em saúde da familia e saúde mental. Tempus, actas de saúde colet, Brasilia. 2016 [cited 2019 Jun 21];10(4):247-263. Available from: http://www.tempus.unb.br/ index.php/tempus/article/view/2363/1721

13. Souza RAF, Caçador BS, Cruz DT, Andrade BMLG, Santos AGL, Veiga AKO. A experiência do trabalho interdisciplinar da Residência Multiprofissional em Saúde Mental. JMPHC. 2016 [cited 2018 Nov 13]:7(1):133-133. Available from: http://www.jmphc.com.br/jmphc/article/ view/473/A\%20experiencia.

14. Magnabosco G, Haddad MCL, Vannuchi MTO, Rossaneis MA. Silva LGC. Opinião de egressos sobre o curso de residência em gerência dos serviços de enfermagem. Semina: Ciências Biológicas e da Saúde. 2015 [cited 2018 Nov 13];36(1Supl):73-80. Available from: http://www.uel.br/ revistas/uel/index.php/seminabio/article/view/19019/16991.

15. Oliveira EB, Carvalho RAC, Teixeira E, Zeitoune RCG, Sabóia VM, Gallasch $\mathrm{CH}$. Fatores intervenientes na formação de enfermeiros residentes: visão de egressos de um programa de residência. REME rev. min. Enferm. 2017 [cited 2018 Nov 13];21:e-1064. Available from: http:// www.reme.org.br/artigo/detalhes/1202.

16. Santos AS, Castro LMC, Fagundes NC, Vieira DFVB. Análise do processo formativo de uma residência de enfermagem em terapia intensiva. Revista Baiana de Enfermagem. 2017 [cited 2018 Nov 13];31(4):e22771. Available from: https://portalseer.ufba.br/index.php/enfermagem/article/ view/22771/15399.

17. Reis TLR, Quadros JS. Programa de residência em enfermagem obstétrica: reflexões a partir da vivência das residentes. Revista de Enfermagem da UFSM. 2017 [cited 2018 Nov 13];7(3):527-538. Available from: https://periodicos.ufsm.br/reufsm/article/view/21259/pdf

RECEBIDO: 26/05/2019 - ACEITO: 10/07/2019 